\title{
DIÁLOGOS (INTER) CULTURAIS EM EDUCAÇÃO E LÍNGUAS: CONCEITOS E DISCUSSÕES ${ }^{1}$
}

\section{DIÁLOGOS (INTER) CULTURALES EN EDUCACIÓN Y EN LENGUAS: CONCEPTOS Y DISCUSIONES}

\section{CULTURAL (INTER) DIALOGUES IN EDUCATION AND LANGUAGE: CONCEPTS AND DISCUSSIONS}

\author{
Adriana Célia ALVES ${ }^{2}$ \\ Nildicéia Aparecida ROCHA ${ }^{3}$
}

RESUMO: Este texto objetiva discutir as várias concepções de cultura ao longo da história e sua influência na educação atual. Com as transformações sociais, cultura não pode ser mais entendida como sinônimo de civilização, seu conceito é visto como móvel, uma mistura de culturas que se conectam umas com as outras; não são puras ou homogêneas, mas híbridas. A sequência textual aqui traçada parte da reformulação do conceito de cultura historicamente e alguns desdobramentos que vão sendo vinculados no campo educacional, em especial a interculturalidade, multiculturalidade e a transculturalidade, que são discutidos neste artigo. Em seguida, compreendemos o papel de cultura no ensino, principalmente no ensino de línguas e discutimos os preceitos da educação intercultural, com o qual nos filiamos e que visa desenvolver a compreensão da própria cultura e da cultura do outro como um processo de respeito, reciprocidade e consciência crítica.

PALAVRAS-CHAVE: Cultura. Ensino. Educação intercultural.

RESUMEN: Este texto objetiva discutir las diversas concepciones de cultura a lo largo de la historia y su influencia en la educación actual. Con las transformaciones sociales, cultura no puede ser más entendida como sinónimo de civilización, su concepto pasa a ser móvil, una mezcla de culturas que se conectan unas con las otras; no son puras o homogéneas, sino híbridas. La secuencia textual aquí elegida parte de la reformulación del concepto de cultura históricamente y algunos desdoblamientos que se van vinculando con el campo educacional, en especial la interculturalidad, multiculturalidad y la transculturalidad, que discutimos en el texto. Luego, compreendemos el rol de la cultura en la enseñanza, principalmente en la enseñanza de lenguas y discutimos los preceptos de la educación intercultural, con la cual no filiamos, y que pretende desarrollar la comprensión de la propia cultura y la cultura del otro en un proceso de respeto, reciprocidad y conciencia crítica.

\section{PALABRAS CLAVE: Cultura. Enseñanza. Educación intercultural}

\footnotetext{
${ }^{1}$ Pesquisa financiada pela Fapesp ( $n^{\circ}$ 2015-13089-5)

${ }^{2}$ Universidade Estadual Paulista (UNESP), Araraquara - SP - Brasil. Doutoranda, conclusão do em Linguística e Língua Portuguesa. ORCID: https://orcid.org/0000-0001-7027-7273. E-mail: c4.adriana@gmail.com

${ }^{3}$ Universidade Estadual Paulista (UNESP), Araraquara - SP - Brasil. Professora Associada da Faculdade de Ciências e Letras de Araraquara. ORCID: https://orcid.org/0000-0003-3815-3785. E-mail: nildirocha@gmail.com
} 
ABSTRACT -This paper aims to discuss the various conceptions of culture throughout history and their influence on current education. With social transformations, culture can no longer be understood as synonymous with civilization, its concept is seen as mobile, a mixture of cultures that connect with one another; are not pure or homogeneous, but hybrid. The textual sequence here is part of the reformulation of the concept of culture historically and some developments that are being linked in the educational field, especially interculturality, multiculturality and transculturality, which are discussed in this article. Next, we understand the role of culture in teaching, especially in language teaching, and we discuss the precepts of intercultural education with which we join and seeks to develop understanding of one's own culture and culture as a process of respect, reciprocity and critical awareness.

KEYWORDS: Culture. Teaching. Intercultural education.

\section{Introdução}

Neste texto discutimos os conceitos de cultura, suas transformações ao longo da história até o conceito atual e como são entendidos contemporaneamente. Em seguida, refletimos sobre as várias concepções decorrentes do deslocamento conceitural de cultura, em especial a interculturalidade, multiculturalidade, transculturalidade e as concepções da educação intercultural.

Partimos de Cuche (2002) para o qual nas línguas orais não existe uma preocupação em definir "cultura". Contudo, ele aponta que nada é natural no homem, isto é, todas as relações, adaptações, ou mesmo as funções biológicas do homem são ditadas pela cultura; cada sociedade possui uma determinada maneira de responder a essas necessidades biológicas e adaptações. Discute-se, assim, que a cultura é tudo aquilo que vem do homem, o que não está relacionado ao humano não é propriedade da cultura.

Cuche (2002) afirma que as definições por raças não são mais satisfatórias para explicar as diferenças entre a humanidade, por isso discute-se cultura para refletir a diversidade humana. Entende-se que o homem é um ser essencialmente cultural e, por meio da cultura, ele se adapta ao meio e também transforma esse meio de acordo com suas necessidades.

De acordo com Cuche (2002, p. 19), a palavra "cultura" tem origem no latim e significa "o cuidado dispensado ao campo ou ao gado". No século XIII, cultura significa "parte uma parcela de terra cultivada". A cultura, nessa época estava relacionada a uma ação ligada ao cultivo da terra. Mesmo no século XVI, quando se pensou no sentido figurado da palavra, esse significado era pouco conhecido e difundido. 
O conceito de cultura no sentido figurado apareceu no século XVIII, na edição de 1718 do Dicionário da Academia Francesa, com complementos "cultura das letras", "cultura das artes". Logo, cultura passou a significar "formação", a "Educação do espírito". Em 1798, perpassada pela ideologia Iluminista, o termo cultura foi associado às ideias de progresso, de evolução e de razão. "É a soma dos saberes acumulados e transmitidos pela humanidade, considerando sua totalidade ao longo da história" (CUCHE, p. 21).

Com o estabelecimento do Estado-nação, no século XV, houve a busca por territórios e a teoria cultural evolucionista atribuiu à sociedade desenvolvida a função de converter os demais habitantes do planeta. Havia uma cultura considerada mais desenvolvida que a outra, e a teoria cultural evolucionista se encarregaria de desenvolver a cultura "inferior".

A cultura manifestava-se, acima de tudo, como um dispositivo útil, consciente, destinado a assinalar as diferenças de classe e salvaguardá-las: como uma tecnologia inventada para a criação e proteção das divisões de classe e das hierarquias sociais (BAUMAN, 2013, p. 10).

Consonante com Cuche (2002), na França, no século XVIII, cultura e civilização possuem conceitos semelhantes, ou seja, impõe-se um conceito de governo instalado pela burguesia, calcado na razão, que projetava tirar a humanidade da "selvageria", "civilizá-la".

Por sua vez, para Bauman (2013), o nome "cultura" foi atribuído a uma missão proselitista, planejada e empreendida sob forma de tentativas de educar as massas e refinar seus costumes e, assim, melhorar a sociedade e aproximar "o povo", isto é, os que estão na "base da sociedade" daqueles que estão no topo da sociedade.

O termo "Kultur" apareceu na língua alemã no século XVIII e possuía a mesma acepção do sentido figurado da palavra francesa, considerada, na época, língua de prestígio. A ideia de cultura foi criada pela classe média intelectual alemã, com o objetivo de distinguir-se da aristocracia que imitava a corte francesa. Segundo Cuche (2002), esse dato poderia significar a afirmação outra forma de legitimidade, uma vez que a classe média se encontrava fora do poder, e também, como todo o povo alemão, por ter uma política e uma consciência nacional incertas, utilizava sua cultura para se glorificar, diferente da França onde, aparentemente, a noção de unidade nacional estava consolidada.

Diferentemente do conceito encontrado na França, civilização e cultura não possuem a mesma acepção. Civilização, na Alemanha, corresponderia ao refinamento de maneiras típicas das classes dominantes, enquanto na França cultura refere-se às produções artísticas dos considerados da classe intelectual. Tem-se uma noção particular na Alemanha, que se opunha à noção universalista de civilização da França. Esse sentido mais amplo na França passou a 
ser compreendido como "[...] um conjunto de caracteres próprios de uma comunidade" (CUCHE, 2002, p. 29).

No século XIX, a cultura era considerada no contexto mundial como um conjunto de conquistas artísticas, intelectuais e morais que constituiam o patrimônio de uma nação. Dessa forma, a cultura era entendida também como uma forma de "[...] orientar a evolução social rumo à condição humana universal" (CUCHE, 2002, p. 31), ou seja, existiam aqueles que eram mais "cultos" que deviam levar a sua "cultura" a outros povos para que todos chegassem ao mesmo nível de "evolução"; "os superiores" deveriam ajudar os considerados "inferiores" para que todos alcançassem a evolução.

O debate entre franceses e alemães sobre as diferentes concepções de cultura se estendeu até o século XX e se tornou base para as discussões posteriores, as quais são revisitadas na próxima subseção.

\section{Cultura: definições contemporâneas}

Tylor (1871), fundador da Antropologia britânica, discute e define o conceito científico de cultura. Sendo assim, ela passa a ser objeto de comparação, de análise e de classificação de cultura ou civilização, tomada em seu sentido etnográfico amplo, é o "[...] conjunto complexo que inclui conhecimento, crença, arte, moral, lei, costumes e quaisquer outras habilidades ou hábitos adquiridos pelo homem como membro de uma sociedade" (TYLOR, 1871 apud Cuche, 2002, p. 35).

A partir desses estudos, surgiram as definições mais recentes de cultura, como as de Kuper (2002), que compreende a cultura como um domínio de comunicação simbólica, sendo que entender cultura significa interpretar os símbolos de forma situada, no fluxo da ação social. Esse autor pontua que os símbolos são criados e recriados na negociação entre as pessoas na interação, ou seja, nos processos intersubjetivos, sendo a ênfase colocada nos aspectos procedimentais, sociais, conflituosos da atribuição de significados. Portanto, nessas visões cultura é interpretada como uma concepção simbólica, social e situada em determinado momento histórico.

Thompson (1995) conceitua quatro denominações de cultura: clássica, descritiva, simbólica e estrutural. A concepção estrutural é a que vai ao encontro dos ideais da pesquisa e dos teóricos citados. O conceito é uma reformulação da concepção simbólica de cultura denominada por Geertz (1973), isto é, a cultura constitui-se de formas simbólicas em 
contextos estruturados, em que o fator sócio-histórico é levado em consideração, por isso possui um caráter dinâmico.

Outra definição que dialoga com a atual realidade globalizada está na intersecção das culturas, na complexidade de cada uma delas, compreendidas por meio da intersecção e não da separação entre elas

As culturas tornam-se interdependentes, penetram-se, nenhuma é um "mundo por direito próprio", cada uma delas tem status híbrido e heterogêneo, nenhuma é monolítica e todas são intrinsicamente diversificadas; há, a um só tempo, "mélange" cultural e globalidade da cultura...A época das viagens intelectuais as periferias silenciosas chegou ao fim (BAUMAN, 2012, p. 58).

A definição de Bauman (2012) dialoga com o conceito de interculturalidade no qual nos apoiamos, pois o sentido da palavra cultura é reinterpretado e visto dessa forma: uma mistura de culturas que se conectam uma com a outra, não são puras ou homogêneas, mas híbridas. Contudo, cremos haver ainda periferias que são silenciadas pelos sistema dominante e, muitas vezes, o trabalho do professor e das pesquisas é não negligenciar essas vozes, darlhes vida e oportunidade de se manifestarem.

Essa ideia pode ser endossada também por Bhabha (1998). Ele discute a cultura ligada ao paradigma pós-colonial, repensando os discursos apregoados na modernidade. Assim, inscrever-se nas teorias contemporâneas é refletir sob uma perspectiva dos "excluídos" da história canônica, os que sofreram dominação, marginalidade, subjugação.

As perspectivas pós-coloniais emergem do testemunho colonial dos países do Terceiro Mundo e dos discursos das minorias dentro das divisões geopolíticas de Leste e Oeste, Norte e Sul. Elas intervêm naqueles discursos ideológicos da modernidade que tentam dar uma normalidade hegemônica ao desenvolvimento irregular e às histórias diferenciadas de nações, raças, comunidades, povo (BHABHA, 1998, p. 239).

Todavia, esse discurso pós-colonial não é construído no binarismo nem nas formas holísticas, mas busca o híbrido e é possível a enunciação de qualquer lugar, por meio do que o autor chama de "transnacional", isto é, não há nacionalidades fixas, elas são sempre moventes.

Órgãos políticos também começaram a se preocupar com a compreensão de cultura, nos moldes pós-modernos, para que isso seja direcionado às perspectivas da Educação.

[...] todo o conjunto de signos pelos quais os membros de uma dada sociedade se reconhecem... uns aos outros, enquanto os distinguem de 
pessoas que não pertencem a essa sociedade. Ela também tem sido vista como "o conjunto distinto de características espirituais, materiais, intelectuais e emocionais de uma sociedade ou de um grupo... (abrangendo), além de arte e literatura, estilos de vida, formas de convivência, sistemas de valores, tradições e crenças. A cultura está no cerne da identidade individual e social e é um componente importante na reconciliação de identidades de grupo em uma estrutura de coesão social. Ao discutir a cultura, é feita referência a todos os fatores que modelam as maneiras de pensar, acreditar, sentir e agir de um indivíduo como membro da sociedade (UNESCO, 2015, p. 12 , tradução nossa) ${ }^{4}$

Com as transformações sociais o conceito de cultura foi reformulado e o debate foi trazido para a Educação. A cultura não é mais a representação exata de um povo, não designa superioridade, mas é um fenômeno híbrido que se relaciona com as identidades individuais e sociais; a partir disso, outros termos foram cunhados para teorizar discussões na Educação, discutidos na próxima subseção.

\section{Concepções de intercultural, multicultural, transcultural}

A partir das definições atuais de cultura, outros termos são buscados para tentar explicar a diversidade/igualdade humana, tais como o multiculturalismo, o interculturalismo, o transculturalismo, entre outros.

A ideia do multiculturalismo surgiu na Europa nos anos 1970, como parte dos movimentos pelos direitos humanos, devido à presença de muitos imigrantes no continente vindos de todo o mundo. Deste modo, a abordagem multicultural compreende a ideia de que várias culturas podem coexistir nos limites de um estado ou sociedade, ela enfoca a diversidade étnica e linguística.

Kumaravadivelu (2008) critica essa concepção do multiculturalismo, porque nessa visão a cultura parece ser imutável e nada se fez para melhorar o acesso daqueles que historicamente não têm privilégios.

Relacionado ao multiculturalismo, de acordo com Dervin e Liddicoat (2013), o termo intercultural foi lançado na Europa nos anos 1980, com a chegada de muitos imigrantes após a segunda descolonização. Então, as discussões sobre a convivência de diferentes culturas em

4 [...] the whole set of signs by which the members of a given society recognize...one another, while distinguishing them from people not belonging to that society." It has also been viewed as "the set of distinctive spiritual, material, intellectual and emotional features of a society or social group... (encompassing) in addition to art and literature, lifestyles, ways of living together, value systems, traditions and beliefs." Culture is at the core of individual and social identity and is a major component in the reconciliation of group identities within a framework of social cohesion. In discussing culture, reference is made to all the factors that pattern an individual's ways of thinking, believing, feeling and acting as a member of society. 
um mesmo território tornaram-se necessárias. De acordo com o autor, esse termo é utilizado de maneira vazia para se referir ao estrangeiro, para dirigir-se ao outro.

De acordo com Auger (2007), os professores que recebiam crianças estrangeiras não sabiam como lidar com esse novo público que falava outra língua materna. Aos poucos foram surgindo representações negativas dos alunos, tais como "[...] os meninos falam mal, como podem aprender a escrever". Dessa forma, os professores precisavam pensar em uma Educação bilíngue ou plurilíngue, consequentemente, multi- ou pluricultural, que visasse à desconstrução de representações negativas e alcançasse o objetivo de integração de estudantes vindos de diferentes partes do mundo.

Dervin e Vlad (2010) apontam que, na União Europeia, o termo intercultural faz referência unicamente a aspectos culturais e, sobretudo à cultura nacional, o que é embaraçoso para esse mundo em que vivemos, com a globalização acelerada permeada pelas intersecções e pela circulação de pessoas. A partir deste lugar teórico, definir cultura nacional passa a ser artificial. Coloca-se, assim, o prefixo inter- que faz referência à interação "[...] o que as pessoas creem quando elas se comunicam junto de várias identidades”.

De acordo com Byram (1997), a ideia de interculturalidade baseia-se no pressuposto de que as culturas diferentes são estruturalmente relacionadas umas às outras, o que geraria oportunidades para encontros e trocas. Por isso, o objetivo da Educação Intercultural seria desenvolver uma competência intercultural que capacitasse o aprendiz a ser mediador de ambas as culturas. Segundo o autor, um falante intercultural é capaz de assumir uma postura de curiosidade e de abertura ao outro, explicar suas crenças, condutas e significados culturais, ao mesmo tempo em que é capaz de compreender o outro e negociar uma forma de interação que seja satisfatória para ambos. Para ele, a competência intercultural seria a capacidade de o indivíduo descentrar-se da sua própria cultura e ter a habilidade de negociar o significado à medida que ele constrói sua identidade como usuário de outra língua. O respeito e a compreensão são incentivados, uma vez que pode haver interações conflituosas. Acrescenta que despertar atitudes reflexivas e questionadoras pode fazer parte de uma competência intercultural. Também se prioriza o ensino da língua para o uso dela em situações que sejam significativas para os aprendentes.

Belz (2003) complementa a posição de Byram (1997) apontando as relações interculturais como ponto de negociação em constante processo de reconstrução.

Compreender os processos interculturais como constitutivos do diálogo é particularmente evidente nos estudos que posicionam diferença como 
pontos-chave ou momentos de negociação em processos de diálogo. Esse estudo acadêmico provavelmente vê todos os encontros dialógicos como inerentemente interculturais embutidos em interesses, identidades e contextos nacionais, políticos, econômicos, religiosos e históricos; eles reconhecem a cultura como algo continuamente sob (re)construção e (re)negociação; eles reconhecem as complexas e diversas redes de relacionamento que nós decretamos dentro e através dos grupos (BELZ, 2003, p. 82).

Por sua vez com Paiva e Viana (2017), na América Latina, apontam que o termo interculturalidade foi incorporado para tratar do diálogo entre os povos tradicionais e indígenas, no intuito de manter uma integração e um equilíbrio entre a necessidade de inserção e a preservação das comunidades, muitas vezes em situações vulneráveis. Deste modo, a Educação intercultural no ensino de línguas emerge das distinções entre indígenas e não-indígenas, nas quais se objetiva equilibrar ou questionar o ensino das línguas dominantes e afirmar o ensino das línguas tradicionais

Dervin e Zehavit (2016) também apontam criticamente que se utiliza o termo intercultural para dizer tudo e nada, para substituir temas problemáticos como raça, cultura, etnia. Há muitas definições e cada pesquisador o compreende de maneira própria. Ele ainda aponta que há confusão entre os termos e que isso pode impactar as abordagens e pesquisas.

Welsch (1994) faz uma crítica ao termo "interculturalismo", dizendo que ele falha ao entender cultura, pois ela é vista como esferas ou ilhas, ou seja, "círculos de felicidade", que colidem, e portanto, necessitam de estratégias para se entender. O próprio Welsch crê e define o termo transcultural para explicar melhor as relações entre as culturas. De acordo com ele, transculturalidadade, entendida em um nível macro, compreende que as culturas, hoje, são extremamente interconectadas umas com as outras, devido ao processo de imigração, à hibridação e às relações com outras culturas.

A nível micro pensa-se no individual, nas construções de identidades individuais e nos estilos de vida, isso tudo interligado a problemas decorrentes do fato de que diferentes culturas precisam viver juntas em uma mesma sociedade, portanto, com espaço para a tolerância, o entendimento e a resolução de conflitos. Assim, a transculturalidade produz diversidade, não é baseada em noções geográficas ou nacionais, mas concebida como um processo de trocas que transpõe questões de território espacial. 


\section{A Cultura no ensino de Línguas}

No começo do ensino comunicativo de línguas, falar sobre cultura, muitas vezes, era mostrar estereótipos, comportamentos, comidas, festas e costumes do grupo de falantes nativos. Como aponta Salomão (2015), este conceito de cultura perpassa a manutenção das características nacionais e há uma falta de profundidade histórica, ou seja, os aspectos culturais são apenas apontados e não discutidos e problematizados. Isso pode levar a perpetuar representações fossilizadas e os (pré) conceitos existentes que, se não discutidos, ou mediados, podem despertar uma representação unívoca e homogeneizada de cultura.

Auger (2007) discute, de acordo com o Quadro Comum Europeu de 2005, um conjunto de conhecimentos culturais e socioculturais (como as crenças, a arte, a moral, a lei, os costumes) pode ajudar o aprendente a melhor compreender a cultura do outro, encorajando a consciência intercultural, que pressupõe o abandono de visões etnocêntricas e permite a abertura a uma cultura estrangeira. Ou seja, repensar os pontos de vistas e os próprios sistema de valores; deste modo, o contato com outra cultura pluraliza as representações interculturais do indivíduo, propicia a ressignificação dos estereótipos negativos.

Sendo assim, devido ao processo de globalização, às dinâmicas das relações interpessoais, ao entrelaçamento de culturas, tem-se a necessidade de instaurar e repensar os processos (inter)culturais e (trans)culturais no ensino-aprendizagem de línguas. Salomão (2015), citando Kumaravadivelu (2008, p. 398), afirma que se precisa considerar o ensino de línguas estrangeiras nos âmbitos global, nacional e individual:

a) realidade global: marcada pela diminuição do espaço e tempo

b) realidade nacional: reação ao ataque de uma homogeneização cultural global;

c) realidade social: família, associações, clubes...

d) realidade individual: indivíduo como tendo identidades múltiplas, contraditórias, dinâmicas e mutantes.

Dessa forma, como sinalizam Dourado e Poshar (2010, p. 21), a educação linguística pode ser compreendida como possibilidade de desenvolvimento e de conscientização de outras culturas diferentes.

Salomão (2015) também considera que o ensino de línguas deve servir para os aprendizes se "[...] posicionarem no mundo globalizado frente a interesses políticos e econômicos, que estão intimamente atrelados a questões de ordem cultural". Portanto, discutir os processos interculturais no ensino-aprendizagem torna-se essencial e não problematizar esses aspectos pode ser perigoso. 
Além da inserção da visão de língua e cultura como indissociáveis, precisa-se repensar o processo de formação de professores de línguas; coadunamos com Salomão (2015) no sentido de que é necessário pensar na formação de professores em três aspectos: alteridade, identidade e representação. Pautamo-nos na perspectiva de que as identidades são múltiplas, a relação e o respeito com o outro são imprescindíveis e somos constituídos de representações que, se não trabalhadas, podem perpetuar os estereótipos e não contribuir para a formação político-social e cultural que se espera de um ensino realmente formador e profícuo.

\section{A Educação Intercultural}

$\mathrm{Na}$ área específica de ensino de línguas, a recorrência do intercultural e sua defesa promoveram um deslocamento na perspectiva de como conceber e atuar em sala de aula, agora com práticas didático-pedagógicas fortemente marcadas em uma abordagem que coloca o conhecimento da cultura e seu dinamismo atual em primeiro plano (PERUCHI, 2010, p 117).

Segundo Luc Collés (2013) a pedagogia intercultural começou na França nos anos 1970 com a dificuldade de ensinar alunos estrangeiros na escola. Posteriormente, a interculturalidade apareceu nos anos 1980 e 1990, com vistas à descentralização, à compreensão do outro e à empatia.

De acordo com a Organização das Nações Unidas para Educação, Ciência e Cultura (UNESCO, 2015), no âmbito educacional há algumas diretrizes para a política educacional mundial, propõe-se que a Educação Intercultural venha para atender às perspectivas vistas na Declaração Universal dos Direitos Humanos (1948):

A Educação deve ser dirigida ao pleno desenvolvimento da personalidade humana $\mathrm{e}$ ao fortalecimento do respeito aos direitos humanos e às liberdades fundamentais.

Promove a compreensão, a tolerância e a amizade entre todas as nações, grupos raciais e religiosos, e promoverá as atividades dos Estados Unidos Nações para a manutenção da paz (UNESCO, 2015, p. 8) . $^{.5}$

Há uma preocupação relacionada à relação entre Educação e cultura. No referido documento é questionada a dificuldade de universalidade e abrangência do conceito de cultura, porque para ser desenvolvido e concretizado, além das questões individuais de cada cidadão, ele depende também das ações dos governos para ser colocado em prática. Por isso, a

${ }^{5}$ Art. 26.2. Declaração Universal dos Direitos Humanos (1948). 
noção de interculturalidade que advém do sentido de promover a tolerância entre os povos por meio da Educação foi discutida e ainda mais aprofundada por outros teóricos.

A partir de textos de 2013, Dervin e Liddicoat apontam que para se compreender a Educação intercultural é preciso desmembrar os componentes óbvios da palavra interculturalidade: o prefixo inter- e a cultura, raiz da palavra. O prefixo inter faz referência às posições intermediárias, entre indivíduos e entre grupos, isto é, na construção da interação a subjetividade é levada em consideração como uma de suas partes constituintes. O prefixo sugere transformação, mistura de reações e comportamentos dos interlocutores (DERVIN; ZEHAVIT, 2016).

Por sua vez, para entender cultura, Dervin e Liddicoat (2013) dizem que, primeiramente, precisamos repensar o conceito da palavra. Apoiado em Bayart (2005), diz que há erros ao compreender cultura como representações estáveis e atemporais, que a cultura possui fronteiras claras e que é endossada por orientações políticas coerentes, isto é, quando a cultura é entendida desse modo, entende-se que todos aqueles associados ao grupo cultural seguem de forma servil a prática cultural associada ao grupo.

Tal autor citando a Abdallah-Pretceille (2013) assevera que cultura pode ser usada estrategicamente como desculpa para justificar comportamentos e pensamentos, ou ser um álibi. Por exemplo, seguindo a prática servil associada a um grupo, "todo brasileiro chega atrasado". Um brasileiro chega atrasado a um compromisso, e usa estrategicamente a desculpa de que chegou atrasado, porque na sua cultura é assim. Para Dervin e Liddicoat (2013), o conceito de cultura também mudou o foco no âmbito das Ciências Sociais. Cultura não é mais vista como representante estática, mas os seres humanos são os impulsores sociais da cultura, lança-se um olhar às inconsistências. Assim, o termo cultura é compreendido como fluido, maleável, permeado por construções subjetivas, em que não apenas a conceptualização de cultura é contestada, mas as realidades representadas pela própria cultura, uma vez que se observa a cultura como ação e não como objeto (ABDALLAH-PRETCEILLE, 2007).

Compartilhamos também da concepção de interculturalidade de Maher (2007), que entende a cultura não como algo hereditário, mas como uma produção histórica discursiva. Sendo assim, ela é uma abstração, é verbo, não substantivo, porque está em constante construção.

Consideramos também relevante trazer a voz de Bauman (2013), para quem a cultura é híbrida, heterogênea, compreendida em determinado espaço de tempo de História, pode ser intersubjetiva, e neste escopo as generalizações são perigosas. Na perscpetica de Bauman, como qualquer outro fenômeno humano, o intercultural é social, ideológico e político 
(DERVIN, ZEHAVIT, 2016). Deste modo, os estudos sobre cultura e intercultura são trazidos para o campo da Educação e, como apontam Dervin e Liddicoat (2013), estão desencadeando mudanças na sala de aula e nas pesquisas. Neste sentido, tais concepções contemporâneas de (inter)cultura dialogam e ressoam em nossas pesquisas.

A partir de tais deslocamentos sobre a Interculturalidade e ensino de línguas, Braga e Bizarro (2005), propõem etapas na elaboração de uma proposta didática que visa à interculturalidade, são elas:

i) sensibilização/ identificação, explorando a dimensão cognitiva e afetiva de conhecimentos, percepções e experiências prévios revelados pelos aprendentes;

ii) observação/ análise dos conteúdos culturais pré-determinados, com o recurso a documentos autênticos (escritos, áudio, vídeo, etc.), que ponham em relevo quer objetos (um alimento, um poema, uma paisagem...) quer comportamentos (verbais e não verbais);

iii) interpretação/ interrelação do que os aprendentes descobriram, em correlação com os respectivos conhecimentos prévios, atuando sobre as novas aquisições;

iv) compreensão/ consciencialização cultural, no confronto interpretativo do diferente com o respectivo código cultural, desenvolvendo atitudes de valorização e respeito recíprocos;

v) empatia, favorecida pela mediação reflexiva, levando os aprendentes a colocarem-se no lugar do Outro e a raciocinarem segundo essa perspectiva, sem criar mitos e/ou complexos nem relativamente a si nem em relação ao (s) Outro(s);

vi) ação, consubstanciada na síntese e na transferência das aprendizagens realizadas e, se possível, no desenvolvimento de representações positivas e atitudes de abertura perante a diversidade linguística e cultural (BRAGA; BIZARRO, 2005, p. 831).

Além de pensarmos nas etapas para a elaboração de atividades interculturais, refletimos também sobre os objetivos da Educação intercultural. Entre eles também se visa a formação de um cidadão intercultural, que, por meio do desenvolvimento da competência intercultural, pode posicionar-se criticamente na sociedade e compreender a diversidade humana sem preconceitos.

A Educação intercultural, portanto, envolve as questões de voz, de identidade, de coconstrução, as capacidades reflexivas e analíticas que buscam, por meio da linguagem, combater as desigualdades, os preconceitos, as opressões e discriminações (DERVIN; LIDICOAT, 2013 p. 15). Também o desenvolvimento da competência intercultural ajuda os falantes a perceberem os fenômenos de injustiças, a questioná-los e optar por um engajamento respeituoso com o outro. 


\section{Considerações Finais}

Uma vez realizado o percurso histórico reflexivo ao qual se objetivou neste texto, apresentando as várias concepções de cultura, multi-trans e intercultura ao longo da história e sua influência na educação atual, ainda coadunamos com Auger (2007) ao considerar que uma didática intercultural deve propor uma reflexão prática sobre a relação de alteridade e diferença, permitir tomar distância das próprias práticas discursivas e sociais, ajudar a relativizar as normas sociais e culturais ao mesmo tempo em que se deve valorizar a tomada de consciência do universo linguístico e humano.

Ressaltamos ainda que, na Educação intercultural é necessário ter cuidado na forma pela qual a cultura é representada para os alunos; é necessário compreendê-la além de uma explicação preguiçosa e conveniente, saindo do de senso comum, generalista que não leva em consideração fatores individuais e históricos (DERVIN E LIDDICOAT, 2013). Visa-se sim ir além da compreensão da cultura como entidade discreta e estática, é mister percebê-la como construções variadas e subjetivas, baseadas em experiências vividas, sendo assim uma proposta de construção de relacionamentos por meio da negociação entre o eu e o outro.

Trazemos a voz que Maher com a qual concordamos (2007, p. 267), ao afirmar que uma Educação para a interculturalidade deve ser levada em consideração a "[...] necessidade de aprender a aceitar o caráter mutável do outro [...] a necessidade de aprender a destotalizar do outro", portanto, não deveria haver padrões ou modelos do outro, pois os grupos são complexos, diversos e múltiplos.

Como podemos verificar, os conceitos de cultura, multi-trans e intercultural aqui mobilizados foram sendo historicamente discutidos e a seu tempo e modo incorporados no campo educacional e no ensino de línguas. Deste modo, verificamos que a ideia de cultura do século XVIII - entendida como sinônimo de civilização, instituída para "civilizar os menos cultos" - ganha outros significados e mobilizam na área educacional outras práticas na atualidade. Neste sentido o processo de globalização dos povos promoveu a proximidade de culturas e os sujeitos passam a ser mais audíveis, provocando assim que o conceito de cultura fosse reinterpretado visto agora com força na dinamicidade do mundo contemporâneo, e que não pode deixar de levar em consideração a contextualização, os aspectos sócio-histórico das sociedades e povos, e a mundial mobilidade dos sujeitos pelo mundo.

Inevitavelmente, como desdobramento da nova concepção de (inter)cultura, a educação intercultural visa uma educação crítica que compreenda a cultura do outro, sua 
própria cultura, com o intuito de desenvolver a tolerância e a reciprocidade nos envolvidos no processo educativo.

\section{REFERÊNCIAS}

AUGER, N. Dépasser les representations. Cahiers pédadogiques, étudier la langue. CRAP. Mai, Paris, 2007, p. 44-47.

BAUMAN, Z. A cultura no mundo líquido moderno; trad. Carlos Alberto Medeiros. 1 ed. Rio de Janeiro: Zahar, 2013.

BAUMAN, Z. Ensaios sobre o conceito de cultura. Rio de Janeiro: Zahar, 2012.

BHABHA, H. K. O local da cultura. Belo Horizonte: Editora UFMG, 1998.

BIZARRO, R.; BRAGA, F. Educação intercultural, competência plurilíngue e competência pluricultural: novos desafios para a formação de professores de línguas estrangeiras. In: Seção de estudos franceses do Departamento de Estudos Portugueses e de CUCHE, D. A noção de cultura nas ciências sociais. 2. ed. Bauru: EDUSC, 2002.

DERVIN, F.; VLAD, M. Pour une cyberanthropologie de la communication interculturelle - Analyse d'interactions en ligne entre étudiants finlandais et roumains. Alsic, [S.L], v. 13, n. 1, p. 1-15, mar./maio 2010. Disponível em:

https://journals.openedition.org/alsic/1399. Acesso em: 15 abr. 2018.

DERVIN, J; LIDDICOAT, A. J. Linguistics for intercultural. 33. ed. Amsterdam: John Benjamins, 2013.

DERVIN, F.; ZEHAVIT, G. Intercultural Competence in education: Alternative Approches for different times. London: Macmillan Publishers, 2016.

DOURADO, M. R.; POSHAR, H. A. A cultura na educação linguística no mundo globalizado. In: SANTOS, P.; ALVAREZ, M. L. O. (Orgs.). Língua e cultura no contexto de português língua estrangeira. Campinas: Pontes, 2010, p. 33-52.

KUMARAVADIVELU, B. Cultural Globalization and Language Education. USA: Yale University Press, 2008.

LUC COLLES. Interculturel et didactique des langues. Youtube, 25 fev. 2013. Disponível em: https://www.youtube.com/watch?v=RYGrXowQa24. Acesso em: 17 mar. 18.

PAIVA, A. F.; VIANA, N. A interculturalidade no ensino de línguas estrangeiras: reflexões acerca da competência (comunicativa) intercultural. In: Portuguese Language Journal, n. 11, American Organization of Teachers of Portuguese - AOTP, Boavista Press, Roosevelt, New Jersey, 2017, p. 234-254.

THOMPSON, J. B. Ideologia e Cultura Moderna. Petrópolis, RJ: Editora Vozes, 1995. 
UNESCO. Guidelines on Intercultural Education. Paris, 2015. Disponível em:

https://www.unesco-sole.si/doc/teme/medkulturno-ucenje-guidelines.pdf. Acesso em: dez. 2018.

WELSCH, W. Transculturality: The puzzling form of cultures today. California Sociologist. v. 17-18, 1994, p. 19-39.

\section{Como referenciar este artigo}

ALVES, A. C.; ROCHA, N. A. Diálogos (inter) culturais em educação e línguas: conceitos e discussões. Revista Ibero-Americana de Estudos em Educação, Araraquara, v. 14, n. 4, p. 2318-2332, $\quad$ out./dez. 2019. https://doi.org/10.21723/riaee.v14i4.12193
e-ISSN:
1982-5587.
DOI:

Submetido em: 25/03/2019

Revisões requeridas: 18/05/2019

Aprovado em: 26/07/2019

Publicado em: 02/09/2019 